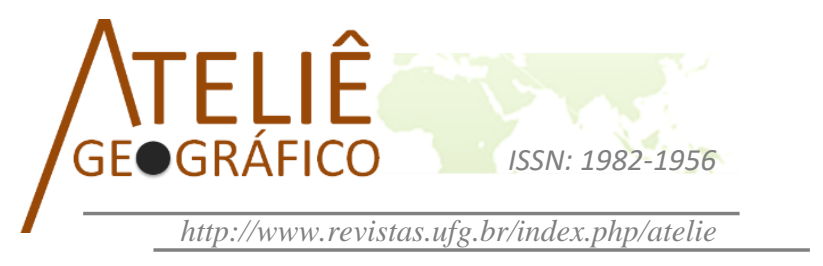

\title{
Índice de qualidade para avaliação de áreas verdes públicas
}

\author{
Quality index for evaluation of public green areas \\ Índice de calidad para la evaluación de áreas verdes \\ públicas
}

Mariana Cristina da Cunha Souza

Fatec de Presidente Prudente-SP

mccunhasouza@hotmail.com

\author{
Margarete Cristiane Costa Trindade Amorim \\ UNESP de Presidente Prudente-SP \\ mccta@fct.unesp.br
}

\begin{abstract}
Resumo
Na ciência geográfica é comum a proposição de procedimentos de análise da qualidade ambiental, estruturados a partir de indicadores ambientais existentes na paisagem, que sejam passíveis de mensuração quali-quantitativa. Assim, o objetivo deste artigo é refletir sobre a sistematização do Índice de Qualidade de Áreas Verdes (IQA) aplicado na área urbana de Presidente Prudente (SP) e destacar a importância da escolha dos indicadores no processo de elaboração do índice. A proposta reflete um esforço metodológico no desenvolvimento de técnicas de avaliação ambiental, mostrando-se viável tanto para a sistematização e padronização de dados primários e secundários quanto para a identificação de padrões de qualidade na escala intraurbana e numa perspectiva espaçotemporal.
\end{abstract}

Palavras-chave: Espaços livres de uso público. Espaço urbano. Indicadores ambientais. Qualidade ambiental.

\begin{abstract}
In geographic science it is common to propose procedures for the analysis of environmental quality, structured from existing environmental indicators in the landscape, which are capable of qualitative and quantitative measurement. Thus, the objective of this article is to reflect on the systematization of the Green Area Quality Index (IQA) applied in the urban area of Presidente Prudente (SP) and to highlight the importance of the choice of indicators in the index elaboration process. The proposal reflects a methodological effort in the development of environmental assessment techniques, proving feasible both for the systematization and standardization of primary and secondary data and for the identification of quality standards in the urban scale and in a spatial and temporal perspective.
\end{abstract}

Keywords: Public spaces. Urban space. Environmental indicators. Environmental Quality. 


\begin{abstract}
Resumen
En la ciencia geográfica es común la proposición de procedimientos de análisis de la calidad ambiental, estructurados a partir de indicadores ambientales existentes en el paisaje, que sean pasibles de medición cualitativa y cuantitativa. Así, el objetivo de este artículo es reflexionar sobre la sistematización del Índice de Calidad de Áreas Verdes (IQA) aplicado en el área urbana de Presidente Prudente (SP) y destacar la importancia de la elección de los indicadores en el proceso de elaboración del índice. La propuesta refleja un esfuerzo metodológico en el desarrollo de técnicas de evaluación ambiental, mostrándose viable tanto para la sistematización y estandarización de datos primarios y secundarios, como para la identificación de patrones de calidad en la escala intraurbana y en una perspectiva espacial y temporal.

Palabras clave: Espacios libres de uso público. Espacio urbano. Indicadores medioambientales. Calidad ambiental.
\end{abstract}

\title{
Introdução
}

A dialética sociedade e natureza sempre interessou à ciência geográfica porque é uma relação que reflete as características, conflitos e particularidades das sociedades em diferentes períodos da história. Sobretudo, a partir do período moderno (século XV), tem-se a relação entre o social e o natural baseada na exploração, isto é, natureza enquanto recurso. Neste cenário, processos históricos como a ascensão e consolidação do modo de produção capitalista concomitantemente à revolução industrial, transformam a maneira pela qual o homem (social) se vê em relação ao meio físico (natural).

As transformações se dão, em um primeiro momento, pela transferência da população residente no espaço rural para o espaço da cidade. Ao mesmo tempo em que $o$ campo é tido como retrocesso, a mecanização das atividades agrícolas condiciona a retirada dos pequenos produtores rurais e reconfigura as relações de trabalho. Às cidades são atribuídos novos papéis e funcionalidades, influenciando na atração de pessoas, pois no imaginário das mesmas é o lugar onde se concentram as melhores oportunidades de emprego e, consequentemente, as melhores condições de vida (Sposito, 1991).

No caso de países ocidentais e periféricos como o Brasil, fatores como os supracitados foram preponderantes para transformar a realidade nas cidades, contribuindo para a sua expansão de modo contínuo e inadequado. Com a expansão, emergiram as altas taxas de concentração demográfica, os problemas sanitários, de moradia e mobilidade, a apropriação de locais inadequados para a fixação de residências (fundos de vale e encostas), a transformação da paisagem e das componentes naturais (impermeabilização do solo, supressão da vegetação, a formação de um clima urbano), os processos de segregação e desigualdade social, entre outros (Mota, 1999).

Assim, com a gradativa diminuição da qualidade ambiental e de vida nas áreas urbanas, promove-se a valorização das pesquisas voltadas às problemáticas recorrentes, especialmente, nas médias e grandes cidades. Pode-se dizer, portanto, que o estudo da 
qualidade ambiental é um paradigma recente para os profissionais responsáveis pelo planejamento e ordenamento territorial urbano (Nucci, 2008).

E uma das principais reflexões levantadas neste contexto é: quais os fatores e/ou variáveis que podem determinar a qualidade ambiental no espaço da cidade?

Pensar em qualidade ambiental é tecer uma concepção relativa. Ao considerar determinadas condições como minimamente qualitativas entende-se que se trata de uma idealização e como tal, está baseada previamente na cultura e no grau de desenvolvimento de cada grupo social. Todavia, a determinação de padrões é fundamental para que as ações voltadas ao planejamento sejam corretamente direcionadas na prática.

Ao destacar a questão espacial e de escala, Machado (1997) argumenta que os padrões de qualidade são variáveis entre as cidades, entre o urbano e o rural, entre países e continentes e, portanto, o que é qualitativo para uma sociedade, pode não o ser para outra.

Nesse sentido, Lima (2013) afirma que definir qualidade ambiental implica, geralmente, em choques conceituais e de procedimentos metodológicos para a sua análise, justamente, porque depende da percepção das diferentes realidades socioespaciais.

Para Mota (1999), a qualidade ambiental resulta da interação entre os elementos naturais e não naturais da paisagem. O autor esclarece que a qualidade do ambiente é possível quando se considera no ordenamento e planejamento do espaço, os benefícios da vegetação com os diversos tipos de uso e ocupação do solo. A vegetação assume papel de destaque nesta definição, uma vez que quando o ser humano se apropria do meio, o primeiro impacto se dá sobre esta componente da biota, que é removida da superfície terrestre.

Desse modo, na tentativa de padronizar procedimentos de pesquisa com fins à análise ambiental, tem sido um consenso o estabelecimento de modelos metodológicos estruturados a partir de atributos existentes na paisagem, que sejam passíveis de mensuração quali-quantitativa. Esses atributos são os indicadores ambientais e servem como recortes, já que estudar todas as variáveis que dinamizam o espaço urbano e que interferem em sua qualidade seria inviável.

Portanto, o objetivo deste artigo é refletir sobre a sistematização do Índice de Qualidade de Áreas Verdes (IQA) aplicado na área urbana de Presidente Prudente (SP), destacando a importância da escolha dos indicadores no processo de sua elaboração.

A dimensão empírica de análise é o município de Presidente Prudente, oficialmente fundado em 1917 e que se localiza na região oeste no estado de São Paulo, nas coordenadas geográficas de latitude $22^{\circ} 7^{\prime \prime}$ sul e longitude $51^{\circ} 22^{\prime \prime}$ oeste. Segundo os dados disponibilizados pelo Instituto Brasileiro de Geografia e Estatística (IBGE), a população da cidade foi estimada em 227.072 mil habitantes no ano de 2018 (Figura 1). 


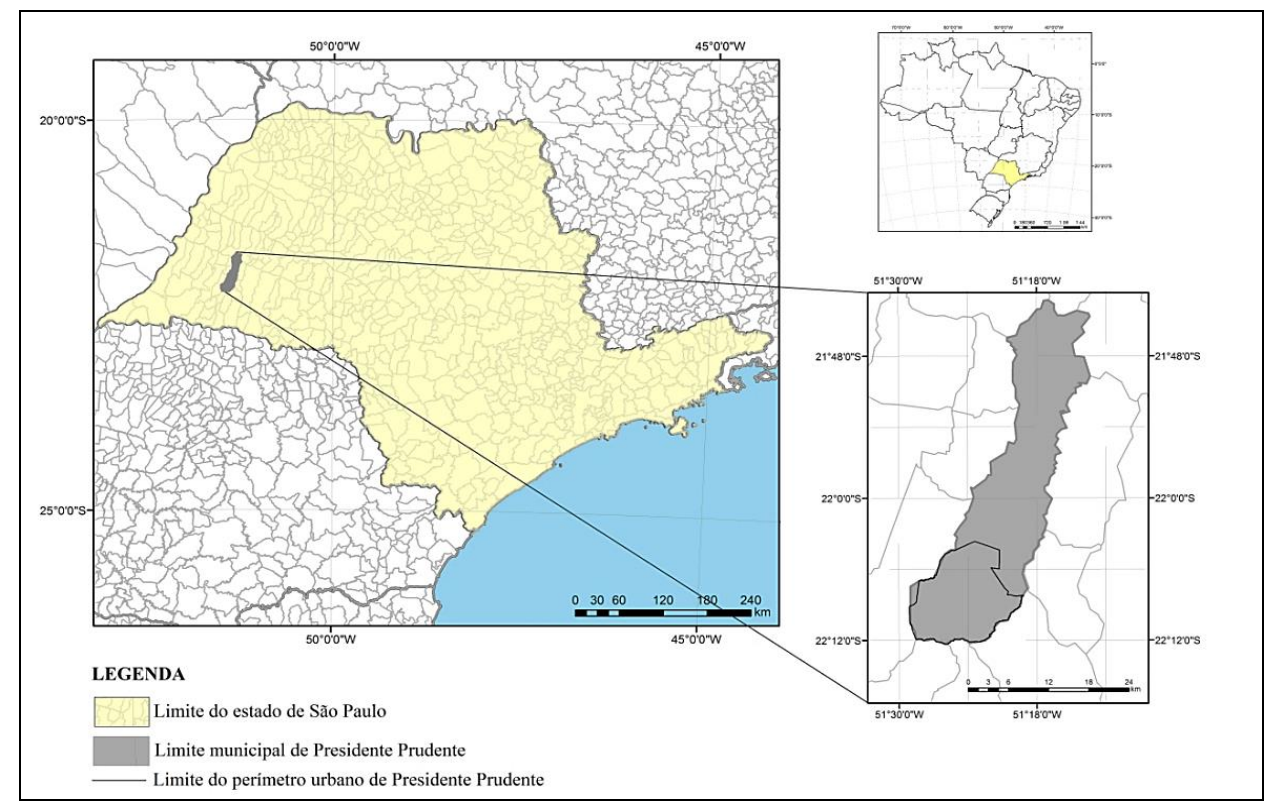

Figura 1: Localização de Presidente Prudente no Brasil e no estado de São Paulo.

Fonte de base cartográfica: IBGE (2010). Convenção cartográfica: DATUM WGS84/Projeção UTM/Fuso 22S. Org.: SOUZA, M. C. C; AMORIM, M. C. C. T. (2016).

Presidente Prudente é a sede da $10^{\mathrm{a}}$ Região Administrativa do estado de São Paulo. No que tange à sua localização próxima à divisa entre os estados do Mato Grosso do Sul e Paraná e sob uma perspectiva dos aspectos socioeconômicos, possui certa atratividade em termos de investimentos privados, polarizando muitos municípios do seu entorno regional, destacando-se nos segmentos do comércio e serviços de apoio às empresas e às famílias, como a educação e a saúde (IBGE, 2015).

\section{Fundamentação teórica: áreas verdes públicas - conceitos, finalidades, funcionalidades e usos}

Nucci (2008, p. 120), um dos principais pesquisadores na geografia sobre o tema qualidade ambiental e a vegetação remanescente no espaço urbano, define áreas verdes como os Espaços Livres onde predominam a vegetação, o solo permeável (pelo menos $70 \%$ de todo a área), de acesso livre e que cumprem fundamentalmente três funções: a estética, a ecológica e a de lazer (Quadro 1). 
Quadro 1: Síntese das funções desempenhadas pelas áreas verdes públicas

\begin{tabular}{|c|c|}
\hline & $\begin{array}{l}\text { É desempenhada, por exemplo, quando os mobiliários e } \\
\text { equipamentos existentes na área estão em bom estado de } \\
\text { conservação e de uso público, possibilitando a prática de atividades } \\
\text { físicas e de lazer pela população. A área verde também contribui } \\
\text { para a dimensão social, na medida em que seu acesso seja } \\
\text { democrático e viabilizado para todos os grupos sociais, seja em } \\
\text { função da sua localização espacial e até mesmo à estrutura física do } \\
\text { terreno. Mesmo que a população não estabeleça uma relação de } \\
\text { valorização para com esses espaços públicos, pela falta de } \\
\text { conhecimento e/ou de incentivo do governo municipal, a sua } \\
\text { implantação proporciona à sociedade um ambiente onde é possível } \\
\text { realizar atividades nos momentos livres e ter contato com } \\
\text { elementos da natureza, por exemplo, flora e fauna (avifauna, } \\
\text { especialmente). }\end{array}$ \\
\hline $\begin{array}{c}\text { Função } \\
\text { ECOLÓGICA }\end{array}$ & $\begin{array}{l}\text { É exercida pela simples existência da vegetação na área verde, bem } \\
\text { como do solo permeável. Ambos os aspectos, em conformidade, } \\
\text { contribuem para reduzir a poluição atmosférica, suavizar } \\
\text { temperaturas extremas tanto no verão quanto no inverno, prevenir } \\
\text { processos de erosão do solo, minimizar a ocorrência de enchentes e } \\
\text { alagamentos, pela absorção da água que escoa sobre a superfície } \\
\text { terrestre, estabilizar o microclima da cidade, dentre outros. }\end{array}$ \\
\hline ESTÉTICA & $\begin{array}{l}\text { Esta é a função mais difícil de ser avaliada, em virtude de sua } \\
\text { dimensão subjetiva, todavia, acredita-se que a mesma seja } \\
\text { desempenhada pela harmonização da área verde em relação à } \\
\text { paisagem urbana, cuja característica principal é a artificialidade } \\
\text { gerada pela intensa massa de concreto e de edificações. É possível } \\
\text { inferir que as áreas verdes também contribuam para o } \\
\text { embelezamento da paisagem, valorizando as diferentes áreas da } \\
\text { cidade, contanto que estejam corretamente manejadas, em bom } \\
\text { estado de uso e conservação, limpas e apresentando um } \\
\text { comedimento entre os elementos que as caracterizam. }\end{array}$ \\
\hline
\end{tabular}

Fonte: Lombardo (1990); Troppmair (1995); Pivetta e Silva Filho (2002); Barbosa, Barbirato e Vecchia (2003). Org.: SOUZA, M. C. C; AMORIM, M. C. C. T. (2016).

Em Presidente Prudente, a qualidade das áreas verdes públicas foi mensurada, tendo em vista os indicadores identificados na paisagem que permitiriam a sua avaliação qualitativa e quantitativa. O conjunto escolhido foi: (a) disposição espacial e densidade da vegetação de porte arbóreo na área verde, (b) aspectos físicos e sanitários da vegetação, (c) cobertura predominante do solo, (d) condição do relevo (voltados à função ecológica); (e) mobiliários e equipamentos existentes (voltado à função social); (f) aspecto geral da área verde (limpeza e conservação) (voltado à função estética). 
Os indicadores foram sistematizados no índice de qualidade, que se configura como um procedimento metodológica para a avaliação ambiental das áreas verdes com base na realidade em perspectiva de análise. Ademais, evidencia a possibilidade de adaptação a outras áreas de estudo, considerando-se a diversidade, as características, pluralidades e particularidades socioespaciais inerentes ao espaço geográfico.

\section{Procedimentos metodológicos: a construção dos dados em campo}

A fim de se obter informações relevantes para a sistematização do índice de qualidade das áreas verdes foi realizado o trabalho de campo, que permitiu um conhecimento mais detalhado sobre a diversidade paisagística, tanto na escala da cidade quanto nas áreas verdes públicas.

A pesquisa empírica foi iniciada com a identificação dos departamentos responsáveis pelo planejamento e ordenamento territorial urbano em Presidente Prudente. O poder público municipal pode ser um parceiro fundamental no desenvolvimento das pesquisas científicas e é uma das forças mais atuantes na produção, estruturação e organização das áreas urbanas. Logo, é uma significativa fonte de conhecimento sobre o recorte espacial analisado.

Assim sendo, foram visitadas a Secretaria de Planejamento, Desenvolvimento Urbano e Habitação (SEPLAN) e a Secretaria de Meio Ambiente (SEMEA), na intenção de se conseguir dados primários e secundários sobre a cidade e as áreas verdes públicas, o que contribuiria para a organização do banco de dados e para as avaliações que seriam realizadas. Por intermédio da SEMEA foi obtida uma lista de áreas verdes cadastradas na Prefeitura Municipal e possíveis de serem georreferenciadas. Após o processo analítico preliminar, tendo em vista o conceito de áreas verdes utilizado, optou-se em trabalhar com um conjunto de 116 áreas.

A lista disponibilizada pela secretaria foi basilar para a realização da pesquisa. A respeito disso, Sanchotene (2004) pontua sobre a relevância do inventário e cadastramento público, como prática fundamental e que deve anteceder as ações de planejamento e ordenamento territorial urbano.

Após a organização da lista final utilizada no trabalho de campo, elaborou-se a ficha de caracterização (Quadro 2), onde estão contemplados os indicadores de qualidade observados na escala da área verde. Autores como De Angelis (2000), Bovo (2009), Minaki (2007) e Gomes (2012), ao trabalharem com as áreas verdes como objeto de estudo, propuseram distintas variáveis e níveis de detalhamento para a caracterização das mesmas. É importante mencionar a questão da flexibilidade quando se utiliza indicadores ambientais, pois os critérios e o nível de detalhe são adaptáveis e definidos pelo pesquisador, conforme os objetivos propostos para a sua pesquisa. $6 \mathrm{Y}$ 
Quadro 2: Ficha de caracterização das áreas verdes públicas

\section{FICHA PARA CARACTERIZAÇÃO DAS ÁREAS VERDES PÚBLICAS}

\section{Pesquisador (a):}

1. Nome:

2. Localização (endereço):

3. Coordenadas - LONG:

LAT:

4. Altitude:

5. Número de identificação:

6. Data da implantação:

7. Data da avaliação:

8. Disposição espacial e densidade da vegetação de porte arbóreo:

\begin{tabular}{|c|c|c|c|}
\hline Bom (_ $)$ & $\begin{array}{c}\text { Satisfatório } \\
\left(\_\right)\end{array}$ & Ruim (_ $\left.{ }^{-}\right)$ & Sem árvores (_ $)$ \\
\hline
\end{tabular}

9. Cobertura predominante do solo:

\begin{tabular}{|c|c|c|c|}
\hline $\begin{array}{c}\text { Péssimo } \\
\text { (impermeável) } \\
\left(\_\right.\end{array}$ & $\begin{array}{c}\text { Ruim (solo } \\
\text { nu/revestido } \\
\text { permeável) } \\
\left(\_\right)\end{array}$ & $\begin{array}{c}\text { Satisfatório } \\
\text { (herbácea) (__ })\end{array}$ & $\begin{array}{c}\text { Bom (herbácea- } \\
\text { arbustiva) (__ })\end{array}$ \\
\hline
\end{tabular}

10. Condições de relevo:

\begin{tabular}{|c|c|c|}
\hline $\begin{array}{c}\text { Fundo de vale } \\
\left(\_\right)\end{array}$ & Vertente (_) & Plana (_ $)$ \\
\hline
\end{tabular}

11. Ocupação predominante no entorno:

\begin{tabular}{|c|c|c|}
\hline Comercial (__ $)$ & $\begin{array}{c}\text { Residencial } \\
\left(\_\right)\end{array}$ & Sem ocupação (_ $)$ \\
\hline
\end{tabular}

12. Aspectos físicos e sanitários da vegetação:

\begin{tabular}{|c|c|c|c|}
\hline Bom (__ $)$ & $\begin{array}{c}\text { Satisfatório } \\
\left(\_\right)\end{array}$ & Ruim (__ $)$ & $\begin{array}{c}\text { Péssimo (Morta } \\
\text { ou com morte } \\
\text { aparente) }\left(\_\right)\end{array}$ \\
\hline
\end{tabular}

13. Mobiliários e equipamentos existentes:

\begin{tabular}{|c|c|}
\hline ITEM & QUANTIDADE \\
\hline Banca de revista & \\
\hline Bancos & \\
\hline Bebedouro & \\
\hline Brinquedos & \\
\hline
\end{tabular}




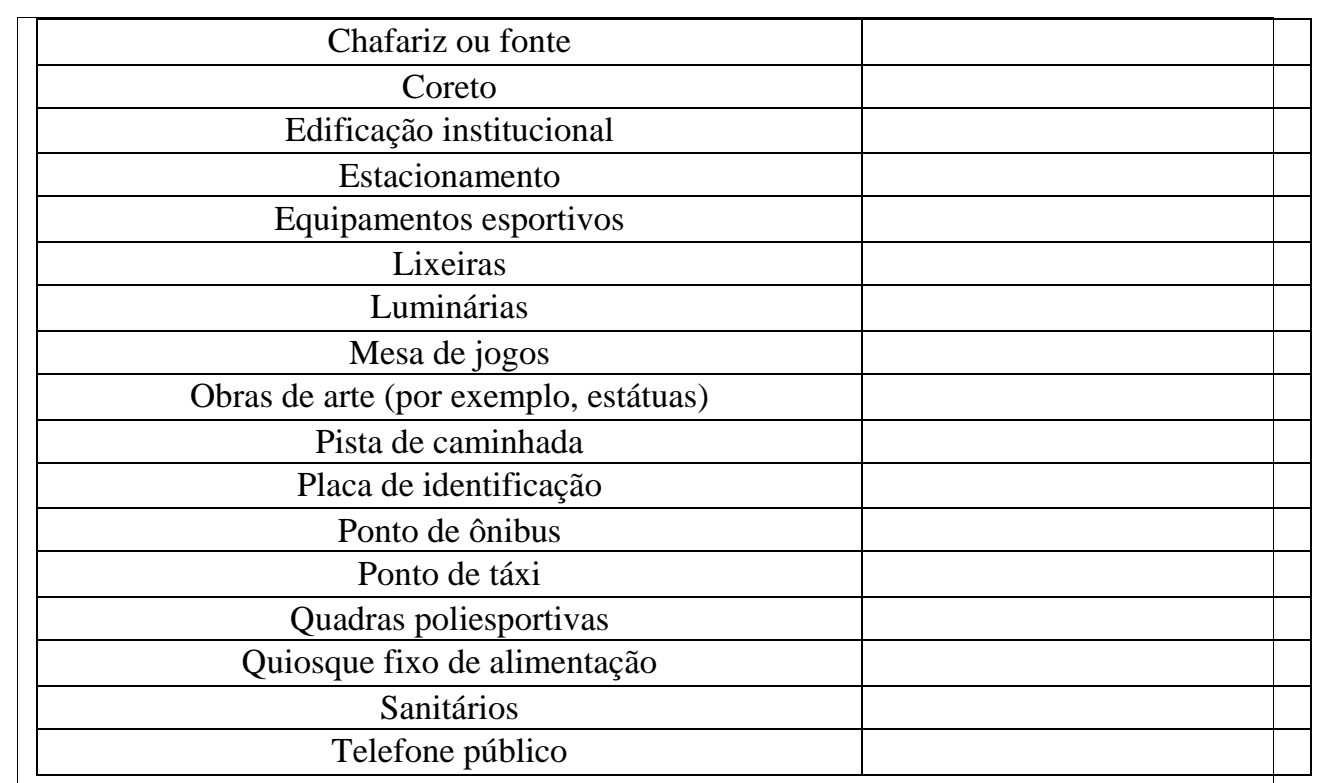

14. Aspecto geral da área verde, no que se refere à limpeza e conservação:

\begin{tabular}{|c|c|c|c|}
\hline Boa (_) & $\begin{array}{c}\text { Satisfatória } \\
\left(\_\right)\end{array}$ & Ruim (__ $)$ & $\begin{array}{c}\text { Péssimo } \\
\text { (Inexistente) } \\
(\longleftarrow)\end{array}$ \\
\hline
\end{tabular}

\section{FICHA DESCRITIVA DAS OCORRÊNCIAS CADASTRADAS E NÃO CONTEMPLADAS NO FORMULÁRIO:}

Adaptado de: Minaki (2007). Org.: SOUZA, M. C. C; AMORIM, M. C. C. T. (2016).

A ficha de caracterização foi adaptada daquela utilizada por Minaki (2007) em sua pesquisa sobre a cidade de Araçatuba-SP. No modelo adaptado, alguns itens de avaliação foram suprimidos e outros inseridos. A análise dos dados obtidos em campo, com base na ficha, foi sistematizada por meio da aplicação do índice de qualidade das áreas verdes e em virtude das suas principais funções: a ecológica, a social e a estética.

\section{Índice de qualidade das áreas verdes públicas (IQA): resultados e discussão}

Pela importância em analisar os dados obtidos em campo, de modo integrado e com rigor científico, no qual a subjetividade do processo analítico fosse diminuída, buscou-se por procedimentos metodológicos intersubjetivos, ou seja, que pudessem ser utilizados como referência e adaptados aos indicadores selecionados para a observação empírica na cidade de Presidente Prudente (Gomez Orea, 1978). 
Inicialmente, identificaram-se índices de caracterização e de qualidade ambiental baseados em áreas verdes públicas urbanas. $\mathrm{Na}$ literatura científica destacaram-se o Índice de Áreas Verdes (IAV) (Toledo; Mazzei; Santos, 2009); de Arborização em Área Urbana (IAUrb) (Gil Duarte; Ziantonio Filho, 2010); de Espaços Livres de Uso Público (IELUP) (Alvarez, 2004); de Cobertura Vegetal em Área Urbana (ICVAU) (Alvarez et al., 2010); de Verde por Habitante (IVH) (Barbin et al., 2008), dentre outros. A maioria deles é gerada em função da variável populacional, contudo, verificaram-se outros mais complexos, como as modelagens e aplicações de algoritmos, por exemplo.

Dentre os índices analisados, optou-se pelo procedimento de Gomes (2012). Na sua dissertação de mestrado, a autora organizou um índice de qualidade para avaliar as praças públicas de Natal (RN), com escala de variação entre de 0 a 1 . Assim, quanto mais próximo de 0, pior são as condições de qualidade na área verde. Em contrapartida, quanto mais próximo de 1 , melhor a qualidade observada. No caso de Natal, assim como em Presidente Prudente, todos os indicadores foram analisados em campo, momento em que foram atribuídos a eles valores relativamente proporcionais, considerando-se os padrões de qualidade julgados como ideais para cada cidade.

Nahas (2009) esclarece que o valor de um índice transcorre das informações numéricas atribuídas a uma variável X. Trata-se, desse modo, de um conceito relacionado à estrutura formal do cálculo. $\mathrm{O}$ índice pode representar temas diversos e ser constituído de dados simples ou compostos (de outros índices).

Para Presidente Prudente foram elaborados três índices parciais, que ao final compuseram o IQA (X4), sintetizando a qualidade das áreas verdes nas três principais dimensões de análise da pesquisa: a ecológica, a social e a estética. Os índices parciais foram: (I) Índice Função Ecológica (X1), composto pelos indicadores, (a) Disposição Espacial e Densidade da Vegetação de Porte Arbóreo na Área Verde (I1), (b) Aspectos Físicos e Sanitários da Vegetação (I2), (c) Cobertura Predominante do Solo (I3), e (d) Condição do Relevo (I4); (II) Îndice Função Social (X2), composto pelo indicador: (a) Mobiliário e Equipamentos Existentes (I5); e (III) Índice Função Estética (X3), composto pelo indicador: (a) Aspecto Geral da Área Verde (Limpeza e Conservação) (I6).

A atribuição de valores aos indicadores parciais obedeceu aos padrões selecionados, de acordo com as principais referências teóricas e metodológicas da pesquisa e ao que foi observado in loco. $\mathrm{O}$ processo mencionado está organizado no quadro 3, onde é possível compreender melhor os indicadores, seus parâmetros de classificação e outros aspectos da avaliação realizada. 
Quadro 3: Modelo parcial do Índice de Qualidade Ambiental das Áreas Verdes

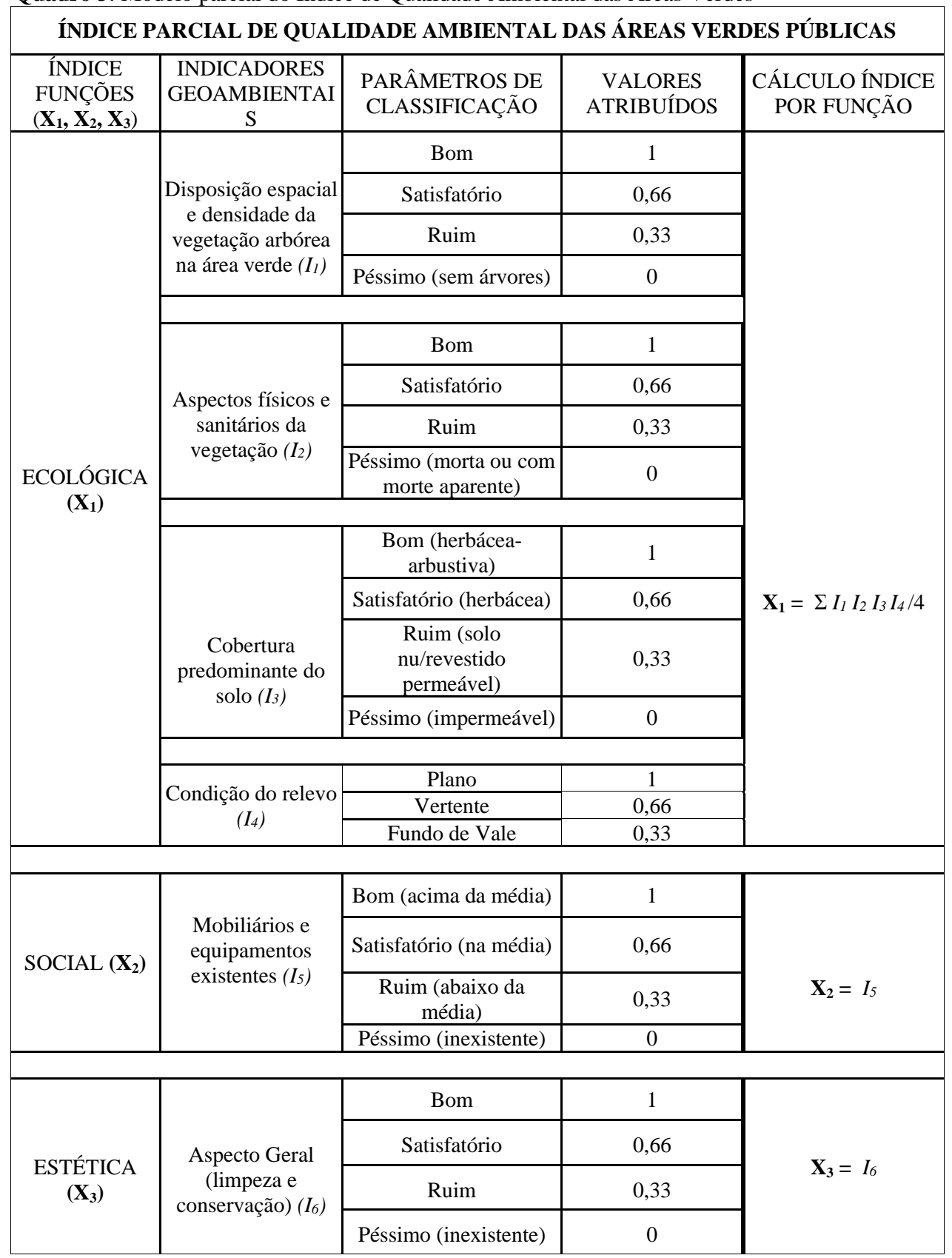

Adaptado de: Gomes (2012). Org.: SOUZA, M. C. C; AMORIM, M. C. C. T. (2016). 
Algumas considerações são importantes. Primeiro, o valor do índice parcial é atribuído conforme os parâmetros de classificação: bom, satisfatório, ruim e péssimo. $\mathrm{O}$ valor máximo de 1 é dividido em quatro frações cujas proporcionalidades são iguais entre elas. Exemplificando, o indicador I1 que se refere à Disposição espacial e densidade da vegetação arbórea na área verde podia receber quatro avaliações com pontuações relativas: péssimo (condição sem árvores), recebe a pontuação mínima de 0; ruim recebe a pontuação 0,33 ; satisfatório recebe a pontuação de 0,66 ; e bom que é considerada a condição mais ideal de qualidade, recebe pontuação máxima de 1 .

Este procedimento foi aplicado para todos os indicadores componentes dos índices parciais, sendo única exceção o indicador Condição do relevo (I4), distinguido em apenas três tipologias: fundo de vale, vertente e plana. A condição menos favorável os fundos de vale - recebeu pontuação de 0,33 .

O índice parcial Função ecológica foi gerado com a aplicação da Equação (1) e a partir de quatro indicadores distintos. Esta condição decorreu da premissa de que as funções social e estética estivessem, primeiramente, condicionadas e dependentes da função ecológica.

$$
\mathbf{X}_{1}=I_{1}+I_{2}+I_{3}+I_{4} / 4
$$

Onde:

$\mathbf{X}_{\mathbf{1}}$ - Índice função ecológica,

$I_{l}$ - Disposição espacial e densidade da vegetação de porte arbóreo na área verde,

$I_{2}-$ Aspectos físicos e sanitários da vegetação,

$I_{3}$ - Cobertura predominante do solo,

$I_{4}$ - Condição do relevo,

4 - Quantidade de indicadores avaliados no índice.

Para conjugar os índices parciais função ecológica, social e estética no IQA, aplicou-se o procedimento metodológico organizado no quadro 4.

Quadro 4 - Modelo final do IQA aplicado às áreas verdes públicas

\begin{tabular}{|c|c|c|c|}
\hline \multicolumn{4}{|c|}{ ÍNDICE DE QUALIDADE DAS ÁREAS VERDES PÚBLICAS } \\
\hline IQA $\left(\mathbf{X}_{4}\right)$ & ÍNDICES PARCIAIS & $\begin{array}{c}\text { CÁLCULO } \\
\text { ÍNDICE FINAL }\end{array}$ & $\begin{array}{l}\text { CLASSIFICAÇÕES } \\
\text { CONSIDERADAS }\end{array}$ \\
\hline \multirow{4}{*}{$\mathbf{X}_{4}$} & Índice função ecológica $\left(\mathbf{X}_{1}\right)$ & \multirow{4}{*}{$\begin{array}{c}\mathbf{X}_{\mathbf{4}}=\sum \mathbf{X}_{\mathbf{1}} \mathbf{X}_{\mathbf{2}} \mathbf{X}_{\mathbf{3}} / \\
3\end{array}$} & Péssimo - 0,00 a 0,32 \\
\hline & Índice função social $\left(\mathbf{X}_{\mathbf{2}}\right)$ & & Ruim $-0,33$ a 0,65 \\
\hline & \multirow{2}{*}{ Índice função estética $\left(\mathbf{X}_{3}\right)$} & & Satisfatório - 0,66 a 0,82 \\
\hline & & & Bom $-0,83$ a 1,00 \\
\hline
\end{tabular}

Adaptado de: Gomes (2012). Org.: SOUZA, M. C. C; AMORIM, M. C. C. T. (2016). 
Quadro 5: Padrões considerados sobre a disposição espacial e a densidade da vegetação de porte arbóreo na área verde

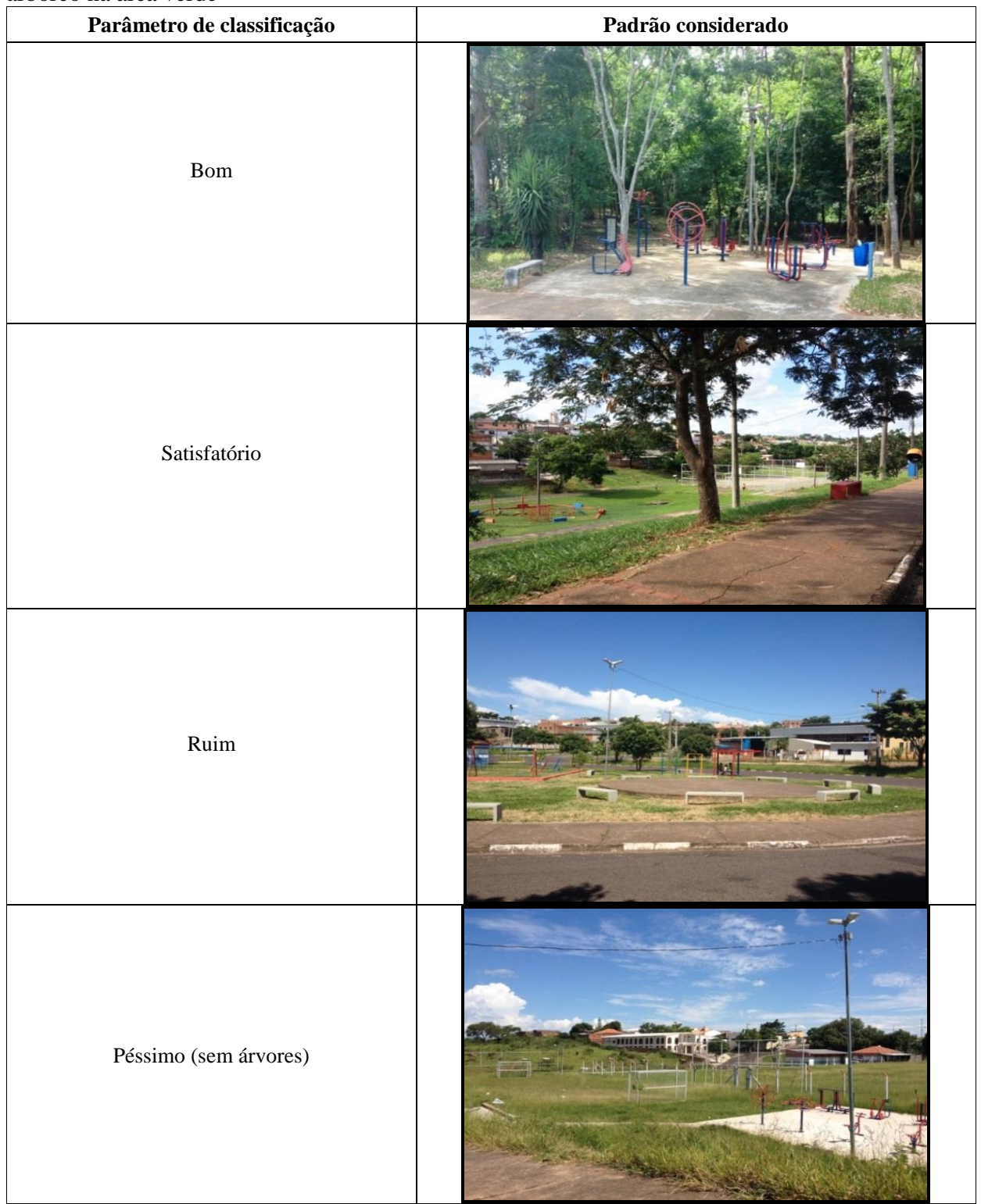

Fotografias e Org.: SOUZA, M. C. C; AMORIM, M. C. C. T. (2015). 
Os parâmetros de classificação bom, satisfatório, ruim, e péssimo são detalhados individualmente para melhor compreensão do que foi observado na área de estudo, evidenciando-se a diversidade paisagística na escala da área verde.

Sobre o indicador Disposição espacial e a densidade da vegetação de porte arbóreo (Quadro 5) foram consideradas ideais as densidades e portes arbóreos maiores, que apresentavam copas mais densas e acima de um metro de altura, acreditando que quanto maior a densidade da vegetação arbórea, mais eficaz é a função ecológica desempenhada pela área verde.

Quadro 6: Padrões considerados sobre os aspectos físicos e sanitários da vegetação

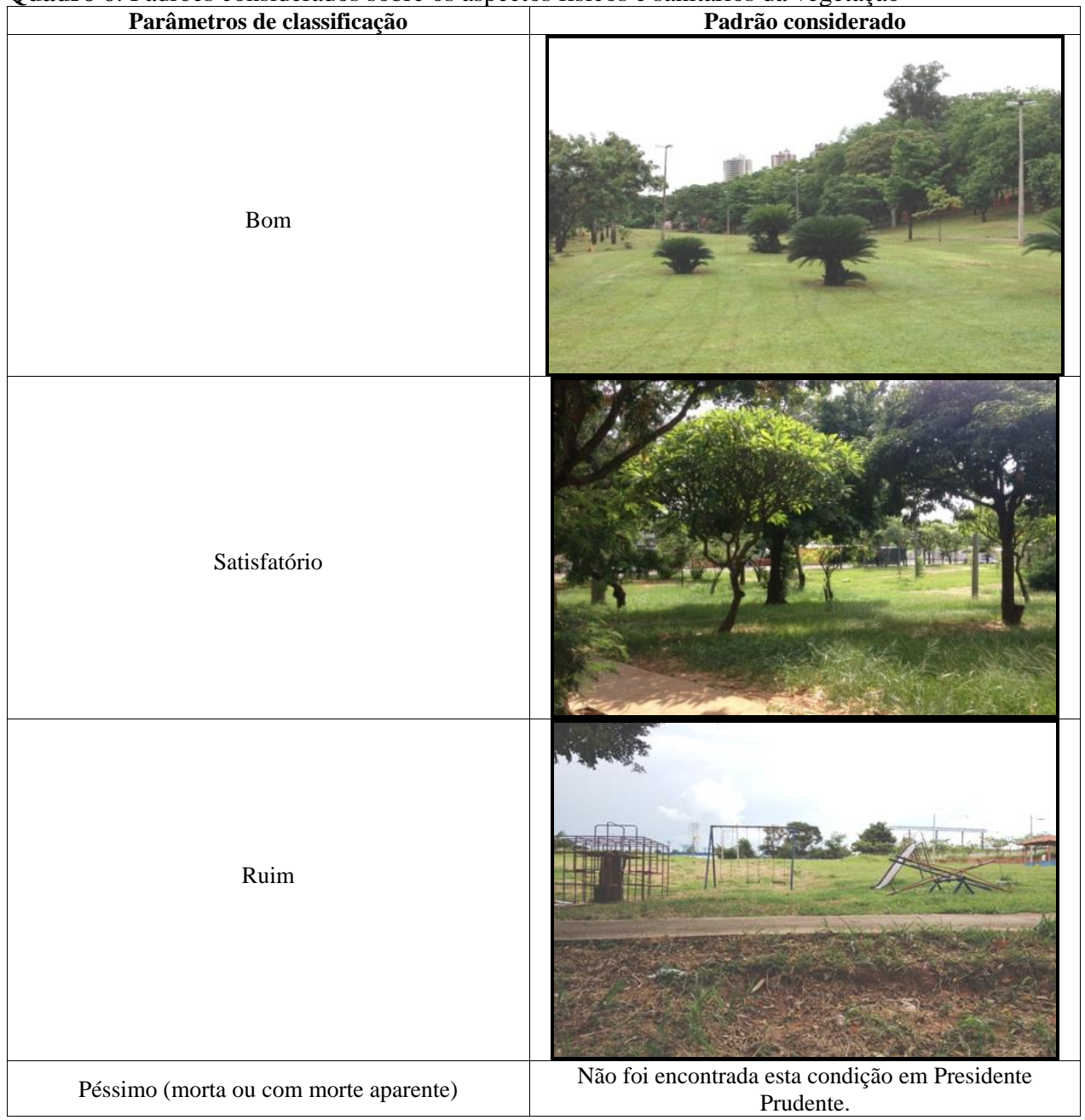

Fotografias e Org.: SOUZA, M. C. C; AMORIM, M. C. C. T. (2015). 
Os diferentes padrões adotados refletem: (a) Bom: presença marcante da vegetação arbórea, onde suas copas se encontram dispostas em proximidade por toda a área verde ou na maior parte dela, sombreando mobiliários e equipamentos, como os bancos, brinquedos e equipamentos esportivos; (b) Satisfatório: presença de vegetação arbórea, mas com copas mais esparsas, possibilitando o sombreamento em determinados pontos da área verde; (c) Ruim: pouca presença de vegetação de porte arbóreo, com suas copas isoladas; (d) Péssimo (sem árvores): inexistência da vegetação de porte arbóreo (Gomes, 2012).

Os Aspectos Físicos e Sanitários da Vegetação é um indicador muito significativo porque uma vegetação saudável proporciona mais benefícios ecológicos para a área verde e seu entorno. Esse aspecto esteve dividido da seguinte forma: (a) Bom: se trata de uma vegetação isenta de sinais de pragas, doenças ou injúrias mecânicas; (b) Satisfatório: se refere à vegetação que apresenta poucos problemas de pragas, doenças ou danos físicos e que necessite, por exemplo, de uma poda; (c) Ruim: denota a vegetação com graves danos decorrentes de pragas, doenças ou físicos; (d) Péssimo (morta ou com morte aparente) (Quadro 6).

Para a Cobertura predominante do solo (Quadro 7) tem-se: (a) Impermeável: área com revestimento impermeável; (b) Solo nu/revestido permeável: apresentado com cobertura permeável, porém, com pouca ou nenhuma presença de vegetação de porte rasteiro; podem ser ainda outros tipos de revestimentos/materiais permeáveis, tais como, pedregulhos; (c) Herbácea: que se apresenta com cobertura de vegetação com porte rasteiro (gramíneas e vegetação rasteira); (d) Herbácea-arbustiva: podem ser cobertas por vegetação rasteira, mas com presença marcante de arbustos.

$\mathrm{Na}$ Condição do relevo, observaram-se três formas características na área urbana de Presidente Prudente: (a) Fundo de vale: refere-se as áreas mais baixas do terreno e por onde escoam as águas das chuvas; (b) Vertente: utilizado na classificação de áreas com qualquer inclinação no terreno; (c) Plano: empregado nas áreas que não apresentavam declividade no terreno.

A condição Fundo de vale recebeu pontuação menos favorável à qualidade ambiental porque em Presidente Prudente foi constatado que as políticas públicas de planejamento, responsáveis pela conservação e preservação dos cursos d'água, não os tem integrado à paisagem urbana, modificando e retificando seus canais fluviais e canalizando-os totalmente (canalização fechada).

Desde o início da expansão territorial na cidade, os córregos e rios urbanos têm sido tratados enquanto problemas ambientais. Nesse sentido, infere-se que as áreas verdes implantadas nas proximidades dos fundos de vale (com raras exceções) acabam subvalorizadas pelo poder público municipal, refletindo no modo como a população se utiliza delas, isto é, depositando resíduos sólidos e tornando-as insalubres e ambientalmente degradadas. 
Quadro 7: Padrões considerados sobre a Cobertura Predominante do Solo

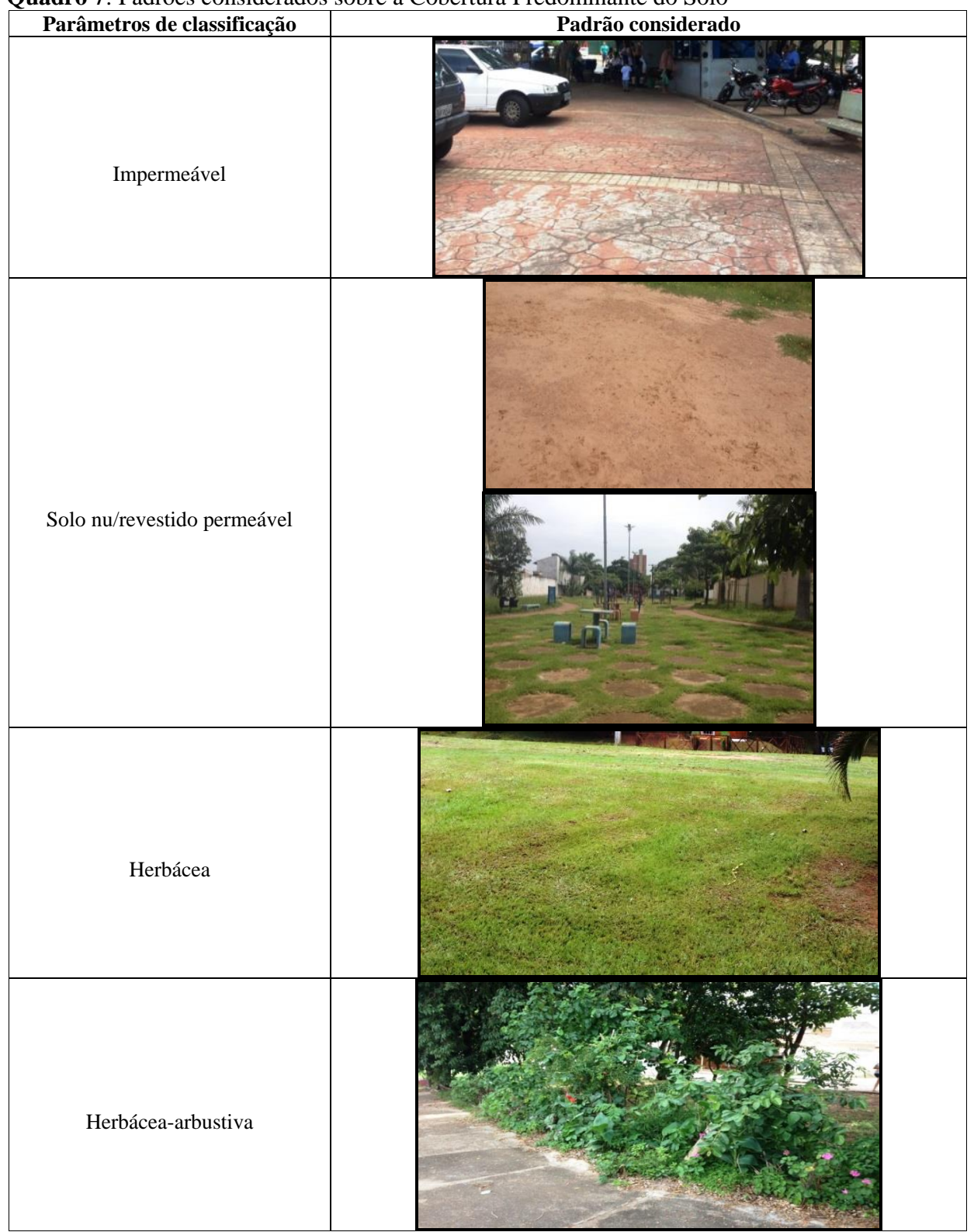

Fotografias e Org.: SOUZA, M. C. C; AMORIM, M. C. C. T. (2015). 
Ademais, a canalização fechada dos cursos d'água contribuí para o aumento do escoamento superficial das águas pluviais, potencializando a ocorrência de alagamentos na área verde em dias de eventos extremos de precipitação, condição frequentemente observada nas áreas que compõem o Parque do Povo, conhecido por suas características físicas, naturais, históricas e por servir de apoio para a realização de eventos culturais e turísticos durante todo o ano na cidade.

$\mathrm{Na}$ análise da Função estética das AVPs, o indicador Aspecto geral da área verde (limpeza e conservação) foi qualificado entre: (a) Bom: refere-se às áreas verdes que apresentaram uma situação boa de conservação, manutenção e manejo dos mobiliários e equipamentos existentes. Também da vegetação presente e da própria limpeza, verificando-se a existência ou não de resíduos sólidos e a presença de folhas mortas, entre outros aspectos; (b) Satisfatório: remete às áreas que apresentaram condições menos favoráveis do que o grupo (a), no que se refere à conservação, manutenção e manejo dos mobiliários e equipamentos, bem como da componente vegetação e da limpeza (presença de resíduos sólidos e de folhas mortas, por exemplo); (c) Ruim: referencia as áreas que se apresentaram carentes de conservação, manejo e manutenção, onde o estado dos mobiliários e equipamentos era de degradação e sem condições de uso público; (d) Inexistente: refere-se às áreas que se apresentaram com características de total abandono (Quadro 8).

Quadro 8: Padrões considerados sobre o Aspecto geral da área verde (limpeza e conservação)

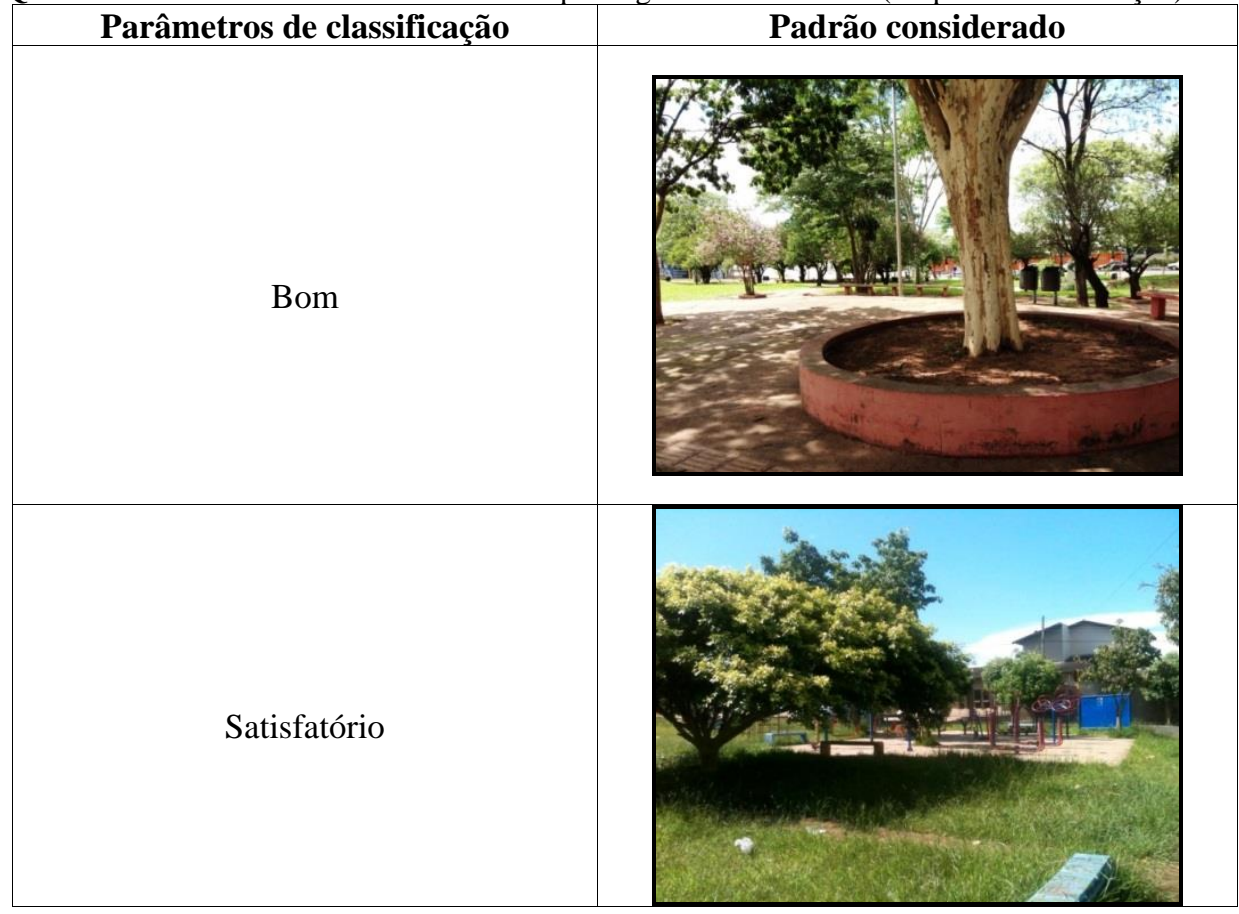




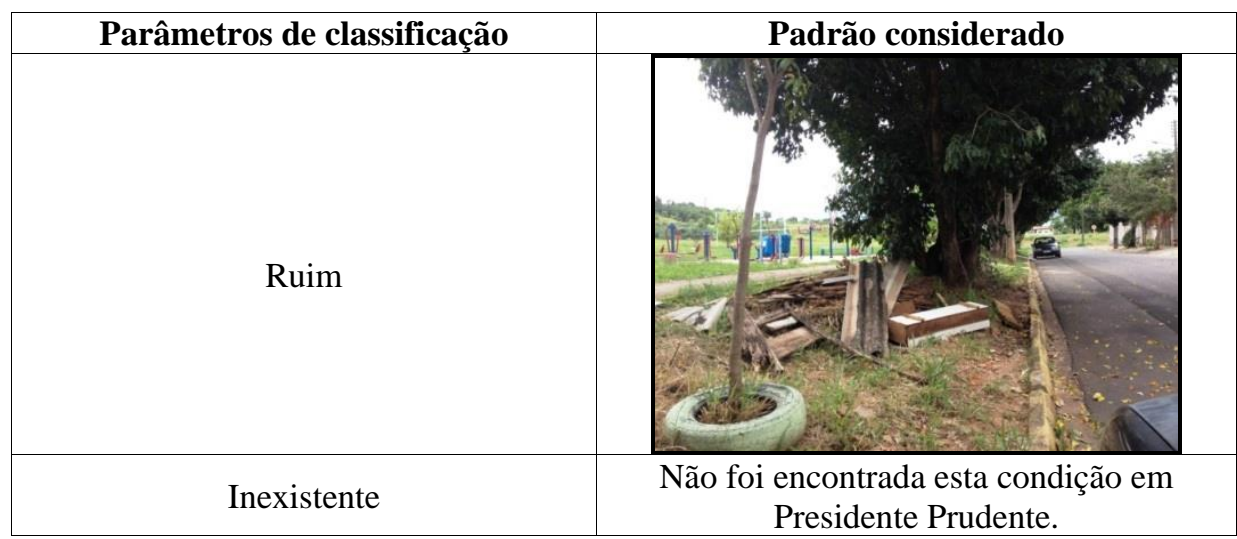

Fotografias e Org.: SOUZA, M. C. C; AMORIM, M. C. C. T. (2015).

Para a análise desse indicador atentou-se, principalmente, a condição da área verde em relação ao tratamento da vegetação, conservação dos mobiliários/equipamentos e a harmonização da paisagem. Para não tendenciar os resultados e a análise da condição encontrada na área verde, foi ponderado que a limpeza realizada pela Prefeitura Municipal obedece a um cronograma de datas previamente direcionadas aos setores visitados na cidade. Portanto, tomou-se como referência o que foi denominado "sensação de abandono" da área verde.

Por fim, na análise da Função Social trabalhou-se com o indicador Mobiliários e equipamentos existentes (Quadro 9). A presença dos mobiliários e equipamentos é importante na atração e permanência das pessoas na área verde, uma vez que grande parte das práticas de uso público é mediada pela sua utilização e pela qualidade no que se refere ao estado de conservação e de uso.

Quadro 9: Relação dos mobiliários e equipamentos analisados nas áreas verdes públicas

\begin{tabular}{|c|c|}
\hline Identificação & Mobiliários e equipamentos \\
\hline 01 & Banca de revista \\
\hline 02 & Bancos \\
\hline 03 & Bebedouros \\
\hline 04 & Brinquedos \\
\hline 05 & Chafariz ou fonte \\
\hline 06 & Coreto \\
\hline 07 & Edificação institucional \\
\hline 08 & Estacionamento \\
\hline 09 & Equipamentos esportivos \\
\hline 10 & Lixeiras \\
\hline 11 & Luminárias \\
\hline 12 & Mesa de jogos \\
\hline 13 & Obras de arte (por exemplo, estátuas etc.). \\
\hline
\end{tabular}




\begin{tabular}{|c|c|}
\hline Identificação & Mobiliários e equipamentos \\
\hline 14 & Pista de caminhada \\
\hline 15 & Placa de identificação \\
\hline 16 & Ponto de ônibus \\
\hline 17 & Ponto de táxi \\
\hline 18 & Quadra poliesportiva e/ou campo de futebol \\
\hline 19 & Quiosque fixo de alimentação \\
\hline 20 & Sanitários \\
\hline 21 & Telefone público \\
\hline
\end{tabular}

Adaptado de: Minaki (2007). SOUZA, M. C. C; AMORIM, M. C. C. T. (2016).

Para Gomes (2012), o conjunto de mobiliários e equipamentos pode ser categorizado em dois grupos: os que permitem ações passivas de uso público, como se sentar, conversar e praticar atividades de mesa de jogos. E os que possibilitam ações ativas, como praticar esportes e exercícios físicos. Desse modo, a disponibilidade de diferentes tipos de mobiliários e equipamentos podem atender as necessidades de determinados grupos, tendo em vista a faixa etária ou as atividades que realizam nesses espaços.

Além de considerar o estado de conservação dos mobiliários e equipamentos, ponderou-se a respeito da quantidade, para que fossem analisados estatisticamente, identificando-se suas frequências e os respectivos percentuais. A frequência foi determinada pelo cálculo da média aritmética, utilizando-se a Equação (2) (Magalhães; Lima, 2005).

$$
\mu=\frac{\sum x}{N}
$$

Onde,

$\mu$ - média.

$\sum X-$ soma dos termos.

$N$ - número de termos.

O tratamento estatístico básico do indicador Mobiliários e equipamentos existentes objetivou mostrar o panorama e a disponibilidade dos mesmos nas áreas verdes públicas de Presidente Prudente, verificando o que era mais recorrente ou básico e menos habitual ou complementares (Figura 2). 


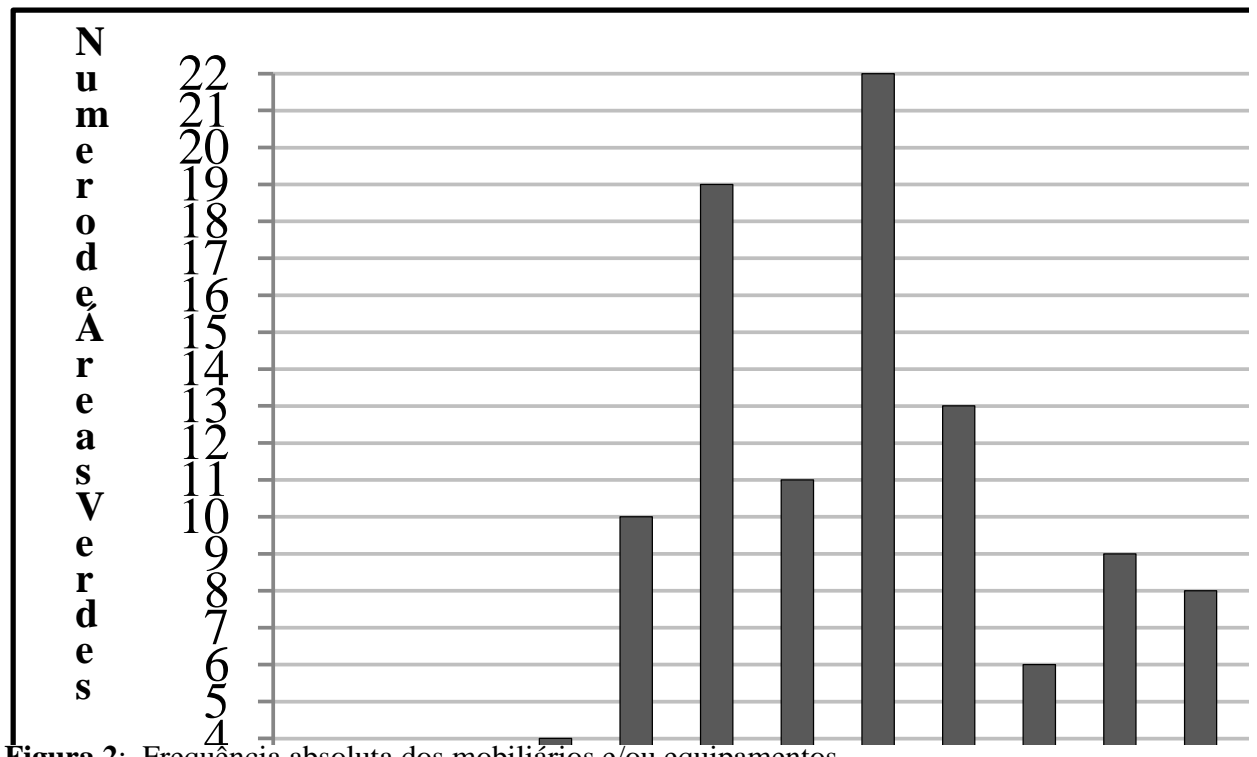

Figura 2: Frequência absoluta dos mobiliários e/ou equipamentos.

Org.: SOUZA, M. C. C; AMORIM, M. C. C. T. (2016).

A partir disto, as áreas verdes foram agrupadas em conjuntos de: acima da média, na média, abaixo da média e onde não foi identificada a presença de mobiliários e equipamentos. Esta forma de se trabalhar com os dados permitiu tecer relações e melhores interpretações do indicador, que é bastante variado, bem como contextualizá-lo na construção do IQA.

A respeito dos parâmetros de classificação empregados - péssimo, ruim, satisfatório e bom, destaca-se que resultou de uma análise subjetiva porque dependeu da percepção da pesquisadora, mesmo que tenham sido consideradas as leituras e os referenciais teóricos e metodológicos do trabalho.

Minaki (2007) esclarece que a percepção é particular em cada indivíduo, estando condicionada por fatores externos como os sociais, culturais e econômicos. Logo, é algo inerente ao processo científico que pode ser minimizado, mas jamais excluído.

Sobre a Ocupação no Entorno, considerou-se que a mesma pode favorecer ou dificultar o direcionamento dos investimentos públicos e privados para setores específicos da cidade, atraindo ou afastando as pessoas para os locais próximos de onde as áreas verdes estão implantadas. Porém, o indicador foi contextualizado durante as análises, após a geração dos índices parciais e final. $\mathrm{O}$ entorno foi diferenciado em: (a) Comercial: refere-se as áreas onde predominam a prática do comércio com farmácias, lojas de roupa e calçados, mercados, restaurantes, posto de combustível e outros; (b) 
Residencial: áreas onde predominam residências, condomínios e loteamentos fechados; (c) Sem ocupação: área não construída.

Ao final da tabulação dos indicadores parciais e da aplicação do índice, os resultados obtidos para a qualidade das áreas verdes públicas em Presidente Prudente, demonstram a condição considerada satisfatória. Apesar de $41 \%$ das áreas verdes estarem avaliadas como ruins, o padrão que reflete a realidade da cidade é positivo porque as classificações satisfatórias $(36 \%)$ e boas $(23 \%)$, somaram $59 \%$ do conjunto avaliado (Tabela 1).

Tabela 1: IQA final

\begin{tabular}{c|c|c|c|c|c}
\hline Avaliação possível & Péssimo & Ruim & Satisfatório & Bom & Total \\
\hline Valor síntese & $0,00-0,32$ & $\begin{array}{c}0,33- \\
0,65\end{array}$ & $0,66-0,82$ & $\begin{array}{c}0,83- \\
1,00\end{array}$ & \\
\hline Quantidade absoluta & 00 & 48 & 41 & 27 & 116 \\
\hline
\end{tabular}

Elaboração: SOUZA, M. C. C; AMORIM, M. C. C. T. (2016).

Pelo modo como foi sistematizado, ou seja, evidenciando a pluralidade paisagística na escala das páreas verdes, acredita-se que a aplicação do índice de qualidade possibilitou a aquisição de resultados confiáveis, que representam a realidade observada na cidade, sendo condizentes com os objetivos propostos e as finalidades da pesquisa científica, tornando as informações mais consistentes e possíveis de serem replicadas cientificamente.

\section{Considerações Finais}

A qualidade ambiental urbana reflete o modo como o espaço é apropriado e produzido em sociedade de tal forma que no âmbito da ciência geográfica, a temática tem se destacado cientificamente e apesar de ser considerada um paradigma recente por alguns autores (Nucci, 2008), observa-se o constante desenvolvimento e aprimoramento teórico e metodológico nas pesquisas relacionadas ao tema.

Apesar de ser uma concepção relativa e baseada em contextos históricos, sociais, culturais, econômicos, entende-se que a definição de qualidade ambiental apresenta uma unidade em meio às distintas conceituações, qual seja, ela é possível desde que haja equilíbrio entre as dimensões sociais e naturais, no processo de produção do espaço.

Dada a sua complexidade, considera-se que o processo avaliativo e metodológico que subsidiou a análise da qualidade nas áreas verdes públicas em Presidente Prudente, somente foi possível por causa da consideração sobre a pluralidade paisagística observada em campo e pelo estabelecimento prévio dos indicadores 
ambientais na ficha de caracterização, permitindo que fossem sintetizados, posteriormente, no IQA.

A aplicação do índice mostrou-se viável tanto para a organização e padronização das informações quanto para revelar os padrões de qualidade numa perspectiva espaço-temporal. Foi verificado que os melhores índices de qualidade estão em setores da cidade considerados de inclusão social ou de baixa exclusão social e naqueles que, historicamente, foram valorizados por meio de políticas públicas de reurbanização, cujos investimentos demonstram a associação entre poder público e o capital privado.

\section{Referências}

ALVAREZ, I. A. Qualidade do espaço verde urbano: uma proposta de índice de avaliação. Tese (Doutorado em Geografia). Escola Superior de Agricultura Luiz de Queiroz. Piracicaba, 2004.

ALVAREZ, I. A. et al. Comparação entre videografia e fotografia aérea para diagnóstico da vegetação em ambiente urbano de Piracicaba (SP). Revista Árvore. vol. 34, n.4. Viçosa (MG), 2010.

BARBIN, H. S. et al. Estudos dos espaços livres do bairro Santa Cecília, em Piracicaba, SP. Revista SBAU, Piracicaba, v.3, n.3. 2008.

BARBOSA, R. V. R.; BARBIRATO, G.; VECCHIA, F. A. S. Vegetação urbana: análise experimental em cidade de clima quente e úmido. Anais... VII Encontro Nacional de Conforto no Ambiente Construído e III Conferência Latino-Americana sobre Conforto e Desempenho Energético de Edificações, Curitiba, PUC - ANTAC, 2003.

BOVO, M. C. Áreas verdes urbanas, imagem e uso: Um estudo geográfico sobre a cidade de Maringá - PR. Tese (Doutorado em Geografia). FCT-UNESP, Presidente Prudente - SP, 2009.

DE ANGELIS, B. L. D. A Praça no Contexto das Cidades: o caso de Maringá-PR. Tese de (Doutorado em Geografia). Faculdade de Filosofia, Letras e Ciências Humanas Universidade de São Paulo. São Paulo, 2000.

GIL DUARTE, D. A. B. et al. Índice de área verde por habitante para o município de Timburi - SP. Anais... XVI Encontro Nacional de Geógrafos. Crises, práxis e autonomia: espaços de resistência e esperanças, espaços de diálogos e práticas. Porto Alegre - RS, 2010.

GOMES, M. R. As praças públicas de Natal no âmbito dos problemas socioambientais urbanos. Dissertação (Mestrado em Geografia). UFRN, Natal, 2012.

GÓMEZ OREA, D. El Medio Fisico y la Planificación. Cuadernos del CIFCA, Madrid, v.1 e v.2, 1978. 
INSTITUTO BRASILEIRO DE GEOGRAFIA E ESTATÍSTICA (IBGE). Brasil, São Paulo, Presidente Prudente. Disponível em:

<https://cidades.ibge.gov.br/brasil/sp/presidente-prudente/panorama>. Acesso em: 17 mar. 2019.

LIMA, V. A Sociedade e a natureza na paisagem urbana: Análise de indicadores para avaliar a qualidade ambiental. Tese (Doutorado em Geografia). FCT-UNESP, Presidente Prudente, SP, 2013.

LOMBARDO, M. A. Vegetação e Clima. Anais... Encontro Nacional sobre Arborização Urbana. Curitiba. FUPEF/PR, 1990.

MACHADO, L. M. C. P. Environmental quality: quantitative and perceptive indicators. In: MAIA, N. B.; LESJAK, H. M. (Coord.) Indicadores ambientais. Sorocaba, 1997. p. $15-21$

MAGALHÃES, M. N.; LIMA, A. C. P. Noções de probabilidade e estatística. São Paulo: Edusp, 2005.

MINAKI, M. As praças públicas de Araçatuba/SP: Análise de um indicador da qualidade ambiental urbana. Dissertação (Mestrado em Geografia). FCT-UNESP, Presidente Prudente, SP, 2007.

MOTA, S. Urbanização e Meio Ambiente. Rio de Janeiro: ABES, 1999.

NAHAS, M. I. P. Indicadores intra-urbanos como instrumentos de gestão da qualidade de vida urbana em grandes cidades: uma discussão teórica-metodológica. In: VITTE, C. C. S.; KEINERT, T. M. M. (Org.). Qualidade de vida, planejamento e gestão urbana. Rio de Janeiro: Bertrand Brasil, 2009. p. 123-153.

NUCCI, J. C. Qualidade Ambiental e adensamento urbano: Um estudo de ecologia e planejamento da paisagem aplicado ao distrito de Santa Cecília (MSP). $2^{\mathrm{a}}$ ed. - Curitiba: O Autor, 2008.

PIVETTA, K. F. L.; SILVA FILHO, D. F. Arborização Urbana. Boletim Acadêmico. UNESP/FCAV/FUNEP. Jaboticabal-SP, 2002.

SANCHOTENE, M. C. C. Conceitos e composição do índice de áreas verdes. In: Boletim Informativo da Sociedade Brasileira de Arborização Urbana, $\mathrm{n}^{\circ}$ 1. 2004, p. 4-9

TOLEDO, F. S. et al. Um índice de áreas verdes (IAV) na cidade de Uberlândia (MG). Revista SBAU, Piracicaba - SP, v.4, n.3, 2009. p. 86- 97

TROPPMAIR, H. As áreas verdes em sistemas urbanos. In: Biogeografia e Meio Ambiente. Rio Claro: Geografia Teorética, 1995.

\section{Agradecimentos}

Agradecimentos ao Conselho Nacional de Desenvolvimento Científico e Tecnológico $(\mathrm{CNPq})$ pela concessão da bolsa de mestrado à primeira autora. 


\section{Mariana Cristina da Cunha Souza}

Bacharela em turismo pela UNESP de Rosana. Doutoranda e mestre pelo Programa de Pós-Graduação em Geografia da FCT/UNESP de Presidente Prudente. Atua como professora de ensino superior na Fatec de Presidente Prudente. Tem experiência nos temas relacionados à qualidade ambiental urbana, áreas verdes públicas, educação ambiental, turismo em unidades de conservação, clima e variabilidade climática.

Endereço: Fatec de Presidente Prudente. Rua Teresina, $n^{\circ} 75$, Vila Paulo Roberto, Presidente Prudente - SP. CEP: 19046-230. Telefone: (18) 3916-7887.

E-mail: mccunhasouza@hotmail.com ou mariana.souza33@fatec.sp.gov.br

\section{Margarete Cristiane Costa Trindade Amorim}

Bolsista de Produtividade em Pesquisa 1C. Livre-docente pela FCT/UNESP. Doutora em Geografia Física pela USP e mestra em Geografia pela FCT/UNESP de Presidente Prudente. Realizou pós-doutorado na Universidade do Porto. Foi coordenadora do Programa de Pós-Graduação em Geografia da FCT/UNESP entre 01/06/2010 e 31/05/2013. Atualmente é professora assistente doutora na FCT/UNESP.

Endereço: FCT/UNESP - Departamento de Geografia Humana e Regional. Rua Roberto Simonsen, $\mathrm{n}^{\mathbf{0}}$ 305, Cidade Universitária, Presidente Prudente-SP. CEP: 19060-900. Caixa-postal: 467.

Telefone: (18) 32295388 - Ramal: 5656 - Fax: (18) 32218212

E-mail: mccta@fct.unesp.br 